\section{Spontaneous activity and water intake in the rat under the effects of scopolamine $\mathrm{HBr}$ and magnesium pemoline}

\author{
P. M. ADAMS* and F. T. CRAWFORD \\ Florida State University, Tallahassee, Fla. 32306
}

Two experiments were conducted to analyze the effects of scopolamine $\mathrm{HBr}$ and magnesium pemoline on spontaneous activity and water intake. Both drugs were found to increase the level of wheel running but with different temporal parameters. Water intake was increased by magnesium pemoline, whereas scopolamine decreased the amount of water consumed during the activity increase. Results are discussed with regard to the interpretation of drug effects on performance in appetitive and nonappetitive reward situations.

Investigations on the effects of orally administered scopolamine $\mathrm{HBr}$ and magnesium pemoline have indicated differences in the directionality of the performance changes. Adams, Crawford, \& Lawrence (1969) found operant performance in extinction to be suppressed by scopolamine $\mathrm{HBr}$ $(10 \mu \mathrm{g} / \mathrm{kg})$ and to be elevated by magnesium pemoline $(20 \mathrm{mg} / \mathrm{kg})$. An earlier study of orally administered magnesium pemoline on runway performance during extinction (Crawford, Adams, \& Warmath, 1969) found that magnesium pemoline produced a faster running speed than did control injections. The present study further investigated the performance effects of these agents on a measure of spontaneous activity and, because of the evidence (Pizzi, See, \& Kohn, 1968; Gerald \& Maickel, 1969) relating the above drugs to appetitive behavior, the amount of water consumed under each drug was determined.

\section{EXPERIMENT 1 \\ Subjects}

The Ss were six male albino rats from the animal colony of the Department of Psychology at Florida State University. The Ss were 120-150 days of age at the start of the experiment.

\section{Apparatus}

The apparatus consisted of six Wahmann activity wheels, each equipped with counters to record revolutions. Each wheel was equipped with a reed switch which would close when a magnet attached to the wheel passed in close proximity. The switch was connected to a 20-channel Esterline-Angus recorder to give a

* Now at the Behavioral Science Laboratory, Department of Neurology and Psychiatry, University of Texas Medical Branch, Galveston, Texas 77550. graphic record of the animal's activity pattern. The wheels were isolated in a temperature-regulated room, with the lighting controlled for a 12-h light-dark cycle.

\section{Procedure}

The Ss were maintained on a $24-\mathrm{h}$ schedule in the wheels throughout the experiment. Daily recordings were made of activity (wheel turns) and the amount of water ingested for a 24-h period. In addition, a 3 -h interval was recorded in the middle of the light phase of the light-dark cycle. The beginning of this $3 \cdot \mathrm{h}$ interval was established by giving each $\mathrm{S} 4 \mathrm{~g}$ of ground Purina chow mixed with $2 \mathrm{ml}$ of water. The end of the 3 -h interval was followed immediately by an additional $8 \mathrm{~g}$ of ground chow with $4 \mathrm{ml}$ of water. Recordings were made of activity and water intake at the end of each hour during this $3-\mathrm{h}$ interval.

Following 20 days of baseline recording of daily activity and water intake for the above intervals, scopolamine $\mathrm{HBr}(10 \mu \mathrm{g} / \mathrm{kg})$ was given to each $S$ for 5 consecutive days. The drug was administered orally with the initial daily feeding at the start of the $3-\mathrm{h}$ interval. Following the 5 days of scopolamine treatment, an additional 5 days of baseline recordings were made on each $S$.

\section{Results}

The daily recordings under scopolamine were compared with baseline records for the same temporal conditions. Figure 1 shows the mean number of wheel turns in the three individual hour records under the 5 days of scopolamine and the 5 postdrug baseline days for the six Ss. For the first $2 \mathrm{~h}$, the mean activity under scopolamine is higher than for the postdrug days. A Kruskal-Wallis one-way analysis of variance of the wheel activity in each of the hour intervals for the scopolamine and postdrug baseline records resulted in a significant difference for the first hour $(p<.02)$ and for the second hour $(p<.05)$. There was no significant difference in the third hour activity records, nor was there a significant difference in the 24-h activity level under scopolamine when compared to the postdrug baseline. Water intake was suppressed significantly for the first hour and for the 24 -h record under scopolamine ( $p<.05)$, but not for the second or third hour. Discussion

The results may be interpreted as giving a temporal analysis of the effectiveness of scopolamine $\mathrm{HBr}$ on the activity and water consumption of the rat for the dosage used. The most effective period was found to be the first hour after the administration of the drug. The length of effectiveness depends on the dependent measure. Spontaneous activity measures indicated $2 \mathrm{~h}$ of effectiveness during which the activity level was elevated. Water intake was most greatly affected during the first hour. The significant decrease in the 24-h water intake indicated that the effects might still be present during the second and third hours, but due to the low level of drinking for these intervals in baseline and drug records, no significant differences were observed. The significant decrease in the 24-h water measure was not attributable solely to the decrease in the first hour following drug administration.

Earlier studies (Carlton, 1963; Walters \& Block, 1969) have noted increased activity under the effects of scopolamine $\mathrm{HBr}$. The present study supports these findings and points out the temporal characteristics of the effects. The measure of water intake supports the suppression noted in many behavioral and pharmacological studies (Stein, 1963; Gerald \&

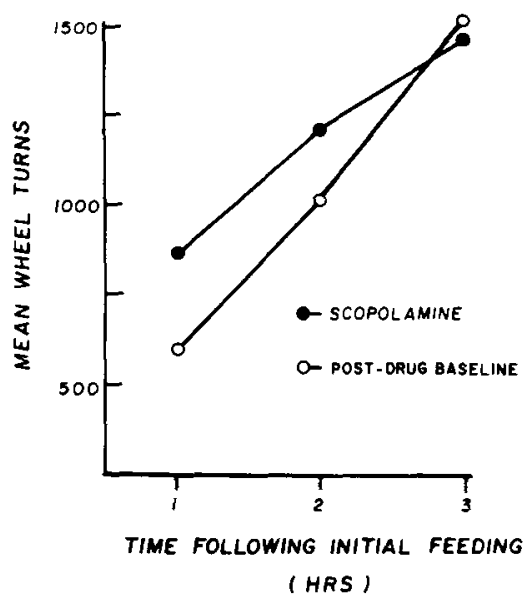

Fig. 1. Mean running for 5 days for individual hour intervals between feedings. 
Maickel, 1969) of a cholinergic component involved in the regulation of water intake. The suppressed operant performance noted by Adams, Crawford, \& Lawrence (1969) may be the result of this water intake suppression, as water was used as the reward in this study. Although no quantitative data were collected on food intake, there was no evidence of eating impairment.

\section{EXPERIMENT 2}

Subjects

Six male albino rats from the animal colony of the Department of Psychology were used in this study. The Ss were 120-150 days of age at the start of the experiment.

\section{Apparatus}

The same six Wahmann activity wheels used in Experiment 1 were used in the second experiment.

Procedure

The Ss were maintained on a daily feeding schedule of $\mathbf{4 g}$ of ground Purina chow and $2 \mathrm{ml}$ of water, followed $3 \mathrm{~h}$ later with $8 \mathrm{~g}$ of chow mixed with $4 \mathrm{ml}$ of water, as in Experiment 1. The Ss were given water ad lib in calibrated drinking tubes, as in the earlier study. Recordings of activity and water intake were measured for a 3- and 24-h interval. Following baseline stability for 20 days, the Ss were given daily oral dosages of magnesium pemoline $(20 \mathrm{mg} / \mathrm{kg})$ for 5 consecutive days. Following this period, a baseline record of postdrug activity and water intake was collected.

Results

The mean wheel turns for predrug, drug, and postdrug 5-day periods are shown in Fig. 2. There was a significant increase in the level of activity under the effects of magnesium pemoline for the $3-\mathrm{h}$ and 24-h measures. A Kruskal-Wallis analysis of variance was significant, $p<.05$, for both of these measures. In Fig. 3 , the mean water intake for the same 5-day intervals is shown. The water intake increased under the effects of magnesium pemoline and returned to the predrug level following the 5 drug days. Significant increases were found for the $3-\mathrm{h}$ and the $24-\mathrm{h}$ intake measures $(p<.05)$.

The above findings support a stimulant interpretation of the effects of magnesium pemoline, as noted earlier by the authors (Crawford, Adams, \& Warmath, 1969). The significant increase in water intake is probably due, in part, to the increased physical exertion noted by the activity measure changes, but possible excitatory effects on appetitive behavior may have importance in interpreting other results involving

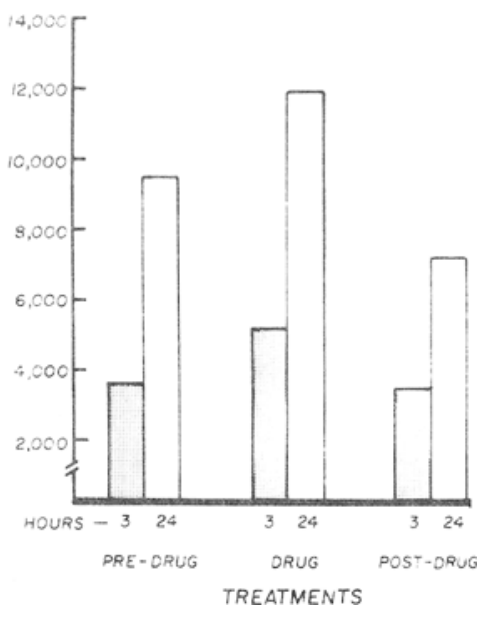

Fig. 2. Mean running for baseline and magnesium pemoline treatments.

performance or learning changes in situations using water reward.

In earlier studies (Adams, Crawford, \& Lee, 1969; Adams, Crawford, \& Lawrence, 1969), water reward was used. The increased performance in extinction in these studies and in others using positive or appetitive reward (Grosser, Sprinthall, \& Sirois, 1967) might be partly a result of the appetitive effects of magnesium pemoline, as well as its stimulant properties. In situations in which increased activity is advantageous to the attainment of a reward or the avoidance of shock, it is necessary to consider the performance effects of magnesium pemoline before making an interpretation. Situations in which increased activity would interfere with

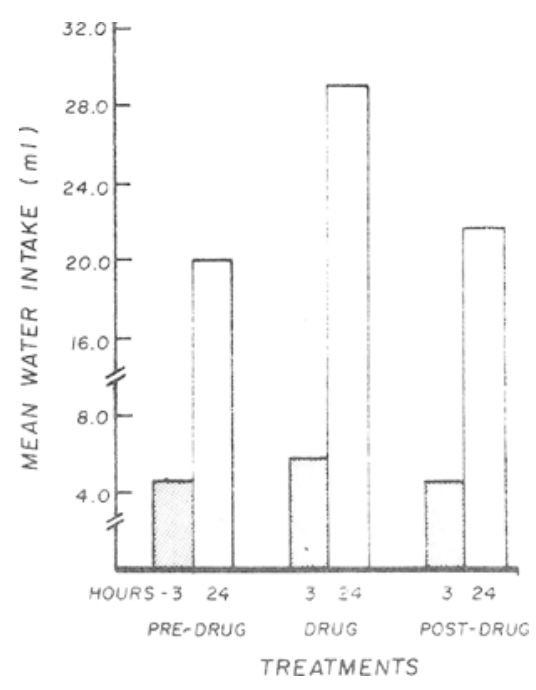

Fig. 3. Mean water intake for baseline and magnesium pemoline treatments. avoidance or the modification of performance to a lower rate of responding have found magnesium pemoline to impair acquisition and performance (Chase \& Rescorla, 1968; Gurowitz et al, 1967). The present study gives further evidence for the stimulant properties of magnesium pemoline and concludes that these are the predominant effects operating in the behavioral changes observed under this drug.

SUMMARY
The effects of scopolamine $\mathrm{HBr}$ on activity and water intake were found to be more limited in both magnitude and temporal characteristics than magnesium pemoline. Although the effects of magnesium pemoline are quite clearly stimulant in nature, the effects of scopolamine appear to be more complex and contain characteristics which are more basic to the regulation of motivational components.

Together, these experiments point out the benefits to be gained by using multiple measures in analyzing the properties of a particular drug. Through such methods, apparent contradictions in the literature can be resolved.

\section{REFERENCES}

ADAMS, P. M., CRAWFORD, F. T., \& LAWRENCE, G. R. Extinction and spontaneous recovery under magnesium pemoline and scopolamine. Psychonomic Science, $1969,17,62$.

ADAMS, P. M., CRAWFORD, F. T., \& LEE W. G. The effects of magnesium pemoline upon repeated acquisition and extinction of a bar press response. Psychonomic Science, 1969,14,101-102.

CARLTON, P. L. Cholinergic mechanisms in the control of behavior by the brain. Psychological Review, 1963,40, 19-39.

CHASE, T. C., \& RESCORLA, R. A. The effect of magnesium pemoline on learning an active avoidance-passive avoidance discrimination. Psychonomic Science, $1968,10,87-88$.

CRAWFORD, F. T., ADAMS, P. M., \& WARMATH, D. S. The effects of magnesium pemoline and runway length on latent extinction. Proceedings of the American Psychological Association. 1969.

GERALD, M. C., \& MAICKEL, R. P. Evidence for peripheral cholinergic components of thirst-induced water consumption. International Journal of Neuropharmacology, $1969,8,337-346$.

GROSSER, G. S., SPRINTHALL, R. C., \& SIROIS, L. Magnesium pemoline: Activation of extinction responding after continuous reinforcement. Psychological Reports, 1967, 1, 11-14

GUROWITZ, E. M., LUBAR, J. F., AIN, B. R., \& GROSS, D. A. Disruption of passive avoidance learning by magnesium pemoline. Psychonomic Science, 1967, 8, 19-20.

PIZZI, W. J., SEE, C. S., \& KOHN, H. M. Effects of magnesium pemoline on food and water intake in rats. Psychonomic Science, 1968, 11, 101-102.

STEIN, L. Anticholinergic drugs and the central control of thirst. Science, 1963 . $139,46-48$.

WALTERS, G. \& BLOCK, R. G. Scopolamine effects on locomotor and exploratory activity in rats. Psychonomic Science, 1969, 17, 3-4. 